Note

\title{
Intermediate Kinematics Produce Inferior Feeding Performance in a Classic Case of Natural Hybridization
}

\author{
Matthew D. McGee, ${ }^{1, \star}$ Joseph W. Reustle, ${ }^{2}$ Christopher E. Oufiero, ${ }^{3}$ and Peter C. Wainwright ${ }^{1}$ \\ 1. Department of Evolution and Ecology, University of California, Davis, California 95616; 2. Department of Life Sciences, Texas A\&M \\ University, Corpus Christi, Texas; 3. Department of Biological Sciences, Towson University, Towson, Maryland \\ Submitted October 9, 2014; Accepted May 29, 2015; Electronically published September 29, 2015 \\ Dryad data: http://dx.doi.org/10.5061/dryad.5g8c5.
}

ABSTRACT: Selection on naturally occurring hybrid individuals is a key component of speciation theory, but few studies examine the functional basis of hybrid performance. We examine the functional consequences of hybridization in nature, using the freshwater sunfishes (Centrarchidae), where natural hybrids have been studied for more than a century and a half. We examined bluegill (Lepomis macrochirus), green sunfish (Lepomis cyanellus), and their naturally occurring hybrid, using prey-capture kinematics and morphology to parameterize suction-feeding simulations on divergent parental resources. Hybrid individuals exhibited kinematics intermediate between those of the two parental species. However, performance assays indicated that hybrids display performance most similar to the worse-performing species for a given parental resource. Our results show that intermediate hybrid phenotypes can be impaired by a lessthan-intermediate performance and hence suffer a larger loss in fitness than could be inferred from morphology alone.

Keywords: functional morphology, suction feeding, ecological speciation, extrinsic postzygotic isolation.

What role does hybridization play in the origin of species? Biologists have long known that interspecific hybrids are common in nature and occur at a range of evolutionary timescales (Müller 1868; Henshaw 1885; Hollick 1888; Elliot 1892; McCormick 1893; Cockayne and Allan 1926). We also now know that many genomes, including our own, bear the signature of past hybridization with closely related species (Heliconius Genome Consortium 2012; Sankararaman et al. 2014). However, it is currently unclear whether hybridization plays a major role in the generation of new biodiversity (Seehausen 2004) or whether it is primarily a reflection of costly mistakes in mate choice by the parental species (Anderson and Stebbins 1954).

* Corresponding author; e-mail: mcgee.matthew@gmail.com.

Am. Nat. 2015. Vol. 186, pp. 807-814. (C) 2015 by The University of Chicago. 0003-0147/2015/18606-55810\$15.00. All rights reserved.

DOI: $10.1086 / 683464$
Most research on hybridization focuses on selection against hybrid individuals, often called postzygotic isolation, which is thought to play a critical role in speciation (Coyne and Orr 1989, 2004; Turelli et al. 2001). Much of this research focuses on intrinsic incompatibilities, which can cause hybrid offspring to be inviable, sterile, or sex biased (Orr and Turelli 2001). Extrinsic postzygotic isolation, sometimes called ecological speciation, also involves selection against hybrid individuals that are viable under laboratory conditions but disfavored by natural selection in the wild (Schluter 1995). Recently, progress has been made on the mechanisms of intrinsic postzygotic isolation (Martin and Willis 2010; Cattani and Presgraves 2012), but we are also starting to understand ecological speciation mechanisms, which depend crucially on ecological interactions (Arnegard et al. 2014).

Hybridization can also create new species directly. In Galapagos finches, hybridization is thought to have given rise to a new, reproductively isolated population of finches that exhibit a beak phenotype and a male song different from those of either of the two parental species (Grant and Grant 2014). Hybridization is often thought to give rise to novel hybrid phenotypes via a phenomenon called transgressive segregation, which occurs when hybrid individuals express trait values that are more extreme than those of either parental species (Bell and Travis 2005). Transgressive segregation has been demonstrated in several of the rapidly evolving cichlid species flocks in East Africa's Rift Valley, suggesting that hybridization may play an important role in rapid adaptive radiations (Seehausen 2004; Selz et al. 2014).

Most work on hybridization focuses on reproductive characters or high-level fitness traits such as growth rate, but less work has been done on the proximal components of organismal performance. However, in order to understand the role of hybridization in evolution, it is crucially important to examine the functional capabilities of naturally occurring hybrids. Here, we examine the functional consequences of 
hybridization in a system where natural hybrids have been studied for more than 150 years.

The freshwater sunfishes and black basses, family Centrarchidae, have long been a focal group in North American ichthyology (Bollman 1891). Work by the ichthyologist Carl Hubbs in the early twentieth century revealed that many putative sunfish species were in fact natural hybrids that could be generated in the laboratory simply by crossing other species (Hubbs and Hubbs 1932; Hubbs 1955). It is even possible to produce intergeneric sunfish hybrids, although these crosses generally have low viability (West and Hester 1966; Bolnick and Near 2005). Sunfish hybrids are morphologically intermediate to the parental types (West and Hester 1966; Neff and Smith 1979). While hybrids are occasionally locally abundant, no evidence suggests that hybridization is able to collapse sunfish species into hybrid swarms, as in stickleback (Taylor et al. 2006), whitefish (Vonlanthen et al. 2012), or Victorian cichlids (Seehausen et al. 2008).

In recent years, sunfishes have become a common subject of ecomorphological studies, especially in relation to the trophic apparatus (Wainwright and Richard 1995; Wainwright 1996; Collar and Wainwright 2006, 2009). Sunfishes are suction feeders that contract their epaxial muscles to elevate the head and rapidly expand the oral cavity. This motion creates a flow of water that draws the prey into the mouth, generally without the fish's jaws ever touching the prey item (Wainwright and Shaw 1999; Ferry-Graham et al. 2003; Higham et al. 2006; Wainwright et al. 2007; Wainwright and Day 2007; Bishop et al. 2008). This feeding method has been extremely well studied in sunfishes, and they are currently the only fish family where feeding kinematics have been comprehensively linked to dietary divergence across the clade (Holzman et al. 2012).

One common sunfish hybrid occurs between bluegill sunfish Lepomis macrochirus and green sunfish Lepomis cyanellus. The two parental species are morphologically and ecologically divergent, with a most recent common ancestor sometime in the middle Miocene (Near et al. 2005). The hybrid of bluegill and green sunfish was described formally as a species no fewer than six times in the 1800 s by a series of famous zoologists, including Lepomis nephelus by Edward Drinker Cope (1868), Pomotis pallidus by Louis Agassiz (1854), Xystroplites gillii and Lepiopomus ischyrus by David Starr Jordan (1877), and several others (Girard 1858; McKay 1881). In the early 1900s, it was shown that this phenotype could be generated by hybridizing a female green sunfish and a male bluegill under laboratory conditions (Hubbs and Hubbs 1932; Hubbs 1955). Despite more than a century and a half of studying this particular natural hybrid, no work exists on functional divergence between hybrids and their parental species.
There is ample reason to believe that hybridization between bluegill and green sunfish has functional consequences. Bluegill have deep bodies and small mouths, while green sunfish have a noticeably larger gape and a more slender body profile. Juvenile and adult bluegill predominantly consume attached and buried macroinvertebrates, such as chironomid larvae (Sadzikowski and Wallace 1976; Werner and Hall 1979). Once located, these prey items are nonevasive, but they can require a powerful suction flow field to dislodge them from their hiding places. Green sunfish generally feed on larger prey items, such as small fishes and odonate larvae (Sadzikowski and Wallace 1976; Werner and Hall 1979). Both of these prey items possess rapid escape responses: fish can rapidly bend and then unbend the body in a "C-start" that allows them to accelerate away from an approaching suction field, while many odonate larvae can rapidly escape via jet propulsion (Mill and Pickard 1975; Domenici and Blake 1997).

In this study, we used high-speed video to examine whether hybrid sunfish feeding kinematics are intermediate relative to those of parental species. We then used suctionfeeding simulation studies, which incorporate information about fish anatomy and prey-capture kinematics, to test how hybrid performance compared to the performance of bluegill and green sunfish on attached and evasive prey.

\section{Material and Methods}

Green sunfish ( $n=5)$, bluegill $(n=5)$, and hybrids $(n=7)$ were captured in Aetna Springs Reservoir, a 0.75-ha irrigation pond on private property in Pope Valley, California (Napa County), with permission from the property owner. According to the property owner, bluegill and green sunfish were never stocked in the pond but were washed in naturally from nearby watersheds several decades ago. Fish were captured by traps and angling from shore. After capture, fish were returned to the laboratory and maintained in 100-L aquaria. Strike kinematics were filmed with live zebrafish (Danio rerio) prey introduced singly into each tank by means of a feeding tube, as in Oufiero et al. (2012). We filmed a minimum of 10 sequences per individual, euthanized each sunfish with an overdose of MS-222, and then fixed each individual in $5 \%$ buffered formalin. We measured standard length (SL), a common measure of body size in fishes, on the preserved specimens.

For each video, four points (fig. 1) were digitized frame by frame with a custom modification of the Dltdv3 package (Hedrick 2008). We used these four points to determine which three videos exhibited the fastest times to peak gape, defined as the time elapsed between $20 \%$ and $95 \%$ of peak mouth opening. We digitized an additional six landmarks for the three fastest videos (fig. 1). Together, these landmarks allowed for measurement of the extent and 


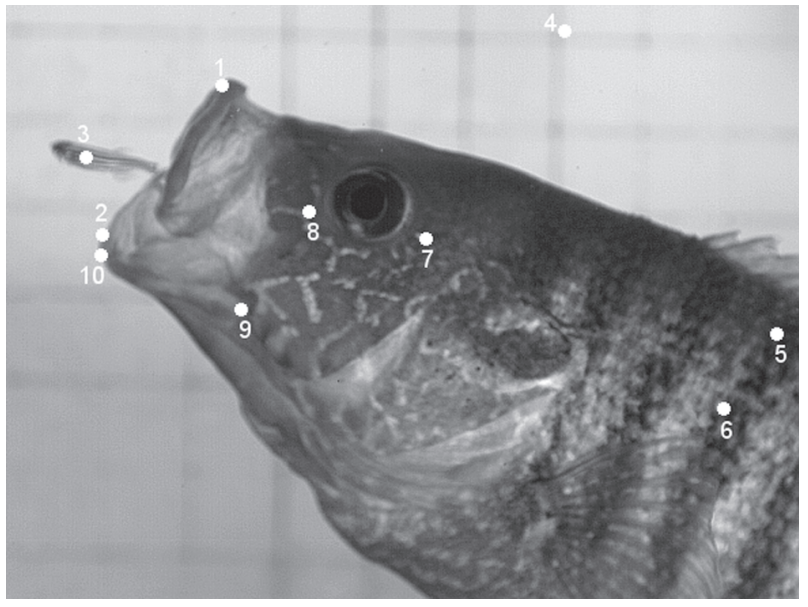

Figure 1: Four points used for SIFF (suction-induced force-field) simulations and determining the fastest times to peak gape: (1) anteriormost inner edge of the upper jaw, (2) anteriormost edge of the lower jaw, (3) estimated center of mass of the prey item, and (4) a stable background point to account for camera motion during filming. We also list an additional six points used for kinematic measurements: (5-6) two stable body landmarks, (7-8) two stable head landmarks, (9) lower-jaw joint, and (10) the anteriormost point on the outer edge of the lower jaw.

timing for maximum gape, jaw protrusion, lower-jaw rotation, and head rotation, as well as strike distance and time to prey capture.

We size-corrected each kinematic variable, using a mixedmodel framework in R with the "Ime4" package (Bates et al. 2014). Species and SL were treated as fixed effects, and individual was treated as a random effect. We then sizecorrected each kinematic variable by subtracting each fish's SL multiplied by the fixed effect of SL and then adding back the mean SL multiplied by the fixed effect of SL. Because kinematic variables are often highly correlated with each other, we performed a principal-components analysis (PCA) on our excursion variables (gape, jaw protrusion, head rotation, lower-jaw rotation, and strike distance) as well as a PCA on the timing variables. We then used a broken-stick model in the R package "vegan" (Dixon 2003) to determine which principal components explained more variation than could be attributed to chance and retained those axes for further analysis. We performed a mixedmodel analysis by regressing each retained principal component against a fixed effect of species and a random effect of individual and then used the "summary" function in the "ImerTest" package to assess significance of the fixed effect of species via the Satterthwaite approximation for degrees of freedom (Kuznetsova et al. 2013).

We measured each fish's capacity to generate suction pressure, using the suction index model (Collar and Wain- wright 2006; Wainwright et al. 2007). Suction index models the feeding system as an expanding cylinder actuated by the epaxial musculature of the fish while accounting for the mechanical advantage of these muscles acting to expand the oral cavity by elevating the cranium (Carroll et al. 2004). We measured the five components of suction index-gape, buccal cavity length, head outlever length, epaxial height, and epaxial width - in each of our individuals.

We then used these empirical measurements to construct simulations of feeding performance. We combined the movement of the four landmarks for each video with suction index to parameterize the suction-induced forcefield model of feeding performance on attached and evasive prey, hereafter "SIFF" (Holzman et al. 2012). The success of a predator in capturing prey via suction feeding is a function of its ability to exert sufficiently high hydrodynamic forces on prey to overcome clinging or evasive defenses. A fish's ability to generate such forces and its success in capturing prey are products of the relative timing of mouth expansion and its approach toward the prey item. SIFF integrates these different components of performance, thus providing an estimate of these forces, and hence provides an index of prey-capture ability.

In the SIFF model, a prey item in a given kinematic sequence can be replaced with a simulated prey that behaves in particular ways. It is even possible to infer performance on a prey type that differs radically from the type used in the actual kinematic sequence. Holzman et al. (2012) were able to infer performance differences within 18 centrarchid species (including Lepomis macrochirus and Lepomis cyanellus) on simulated attached, flow-sensitive, and visually evasive prey, using only kinematic sequences from attached prey. These inferred performances on simulated prey are correlated with dietary data from wild centrarchid populations (Holzman et al. 2012). SIFF has also been successively used to infer performance on evasive and attached prey in the sleeper goby Gobiomorus dormitor, using kinematic sequences from evasive prey (Martin et al. 2015). As in centrarchids, these inferredperformance differences matched dietary data from wild populations.

We used two types of simulated prey: attached prey, which correspond to the diet of adult bluegill, and evasive prey, which correspond to the diet of adult green sunfish (Werner and Hall 1979). For strikes on attached prey, we used SIFF to record the maximum hydrodynamic force exerted on a simulated $2 \times 1-\mathrm{mm}$ nonevasive prey item. For strikes on evasive prey, we chose to simulate a Gambusia mosquitofish, as they are eaten by green sunfish at our study site (P. C. Wainwright, unpublished data). In addition, the escape performance of a closely related species of Gambusia has been studied in detail (Langerhans 2009), allowing us to parameterize the escape trajectory 
and acceleration. SIFF was parameterized such that Gambusia initiated an escape response when the predator approached within half a body length of the prey. We first simulated a low Gambusia escape force of $0.01 \mathrm{~N}$. If the Gambusia was captured, we successively increased its escape force by $0.01 \mathrm{~N}$ until the predator failed to capture it. We then recorded evasive-prey performance as the maximum Gambusia escape force the predator could successively overcome. For both performance measures, we recorded each fish's maximum performance as the average of the three strikes with either the highest force exerted on the attached prey or the highest evasive-prey escape force the predator could overcome. We removed the effect of predator size with a linear regression on SL and species and then used the coefficient of SL to replace each fish's SL with the mean SL. We then analyzed performance from our evasive- and attached-prey simulations, using a Wilcoxon rank-sum test with a Holm correction for the number of tests.

We also examined whether the hybrid performance mean was farther from that of the better-performing parent on a given resource than would be expected by chance. We calculated the absolute value of the distance between the species means of hybrids and bluegill for attached prey and that between the means of hybrids and green sunfish for attached prey, and then compared those values to a distribution of 10,000 randomly sampled values of those same distances sampled without replacement, using the "sample" function in R. We then repeated the test for evasive prey.

\section{Results}

For our excursion-variables PCA (fig. 2), only one principal component, explaining $84.3 \%$ of variation, was retained by the broken-stick model. Gape, head rotation, lower-jaw rotation, and strike distance all loaded heavily on PC1 (table 1a). Mixed-model analysis revealed that bluegill were significantly different from green sunfish $(P<.001)$ and hybrids $(P<.05)$ on excursion PC1; likewise, green sunfish were significantly different from hybrids $(P<.01)$. For PCA with kinematic timing variables (fig. 2), a broken-stick model retained only one principal component that explained $46.6 \%$ of variation, with all six timing variables loading heavily (table 1b). A mixed-model analysis indicated no significant differences between bluegill and green sunfish $(P=.69)$, between bluegill and hybrids $(P=.66)$, or between green sunfish and hybrids $(P=.39)$ on timing PC1. All data have been archived in the Dryad Digital Repository: http://dx.doi.org/10.5061/dryad.5g8c5 (McGee et al. 2015).

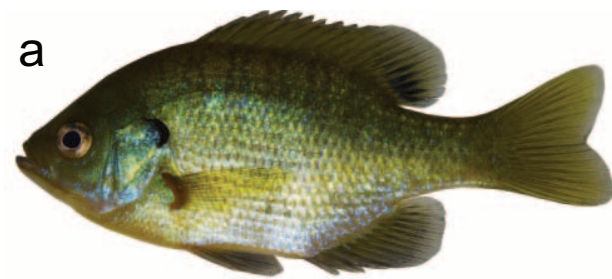

Bluegill, Lepomis macrochirus

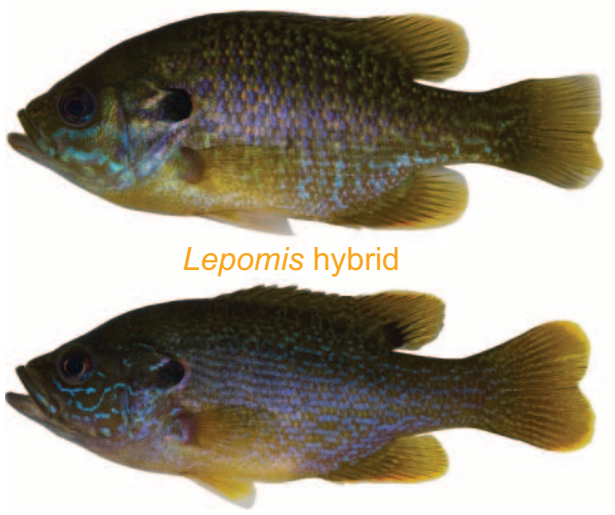

Green sunfish, Lepomis cyanellus

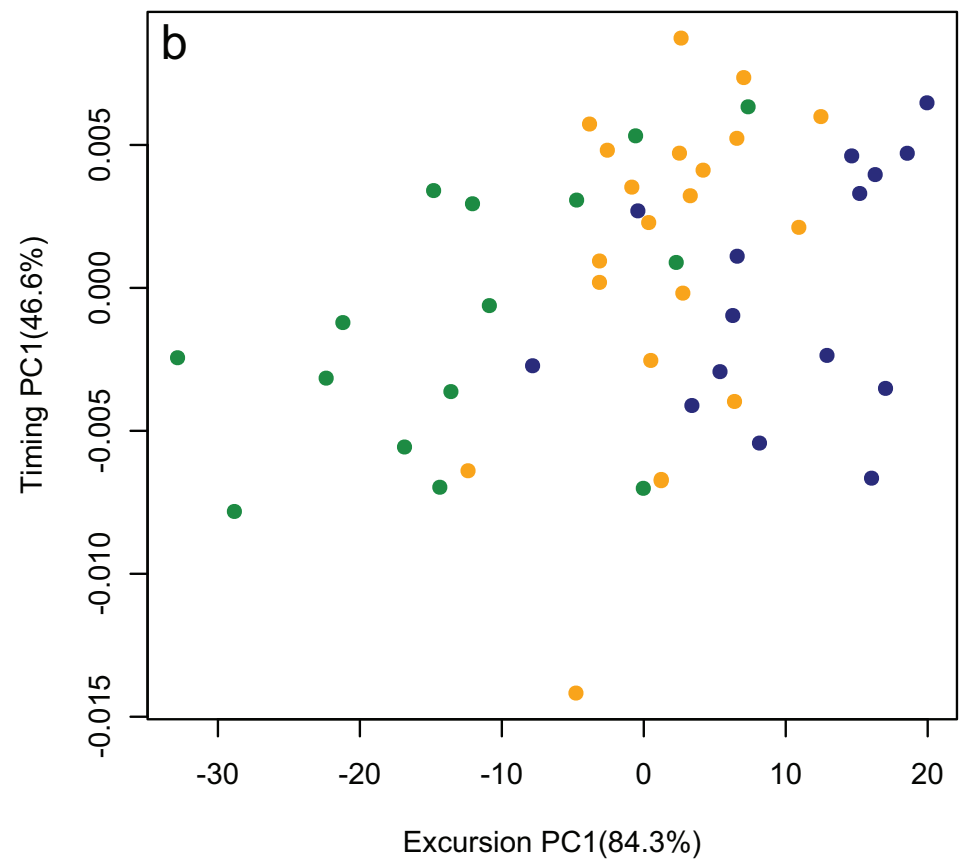

Figure 2: Kinematic divergence in two centrarchid species and their hybrid. $a$, Lateral photographs of live bluegill (Lepomis macrochirus), green sunfish (Lepomis cyanellus), and their hybrid. Note differences in body depth, mouth size, and color. $b$, Plot of principal component 1 (PC1) for prey-capture excursion variables ( $X$-axis) versus PC1 for timing variables ( $Y$-axis). Point colors correspond to species labels in $a$. 
Table 1: Loadings from principal-components (PC) analysis of excursion variables and of timing variables

\begin{tabular}{|c|c|c|c|c|}
\hline & \multirow[b]{2}{*}{ PC1 loadings } & \multicolumn{3}{|c|}{ Mean values } \\
\hline & & Bluegill & Hybrid & Green sunfish \\
\hline \multicolumn{5}{|l|}{ a. Excursions: } \\
\hline Gape & -.175 & 11.04 & 14.98 & 17.80 \\
\hline Jaw protrusion & -.007 & 5.93 & 5.15 & 7.07 \\
\hline Cranial rotation & -.437 & 11.18 & 15.22 & 22.965 \\
\hline Lower-jaw rotation & -.859 & 33.65 & 40.04 & 51.11 \\
\hline Strike distance & -.203 & 9.82 & 13.30 & 14.94 \\
\hline \multicolumn{5}{|l|}{ b. Timings: } \\
\hline Gape & -.254 & .00997 & .00959 & .01021 \\
\hline Jaw protrusion & -.403 & .01118 & .00786 & .01040 \\
\hline Cranial rotation & -.383 & .01398 & .01189 & .01223 \\
\hline Lower-jaw rotation & -.486 & .01181 & .01291 & .01464 \\
\hline Time to prey capture & -.625 & .01103 & .01217 & .01187 \\
\hline
\end{tabular}

Note: Mean values for the excursion variables are reported in millimeters (gape, jaw protrusion, and strike distance) or degrees (cranial rotation and lower-jaw rotation). Mean values for timing variables are reported in seconds.

A Wilcoxon test of differences among parental species and the hybrid in their success in capturing attached prey (fig. 3), as estimated with our SIFF model, reveals that bluegills were significantly more effective than either green sunfish or hybrids $(P<.05$ in both comparisons). Green sunfish and hybrids did not differ in their ability to capture attached prey $(P=.34)$. For the SIFF simulation of capture of evasive prey (fig. 3), we found that green sunfish were significantly better at generating force for capturing evasive prey than were either bluegills or hybrids $(P<.05$ in both com-

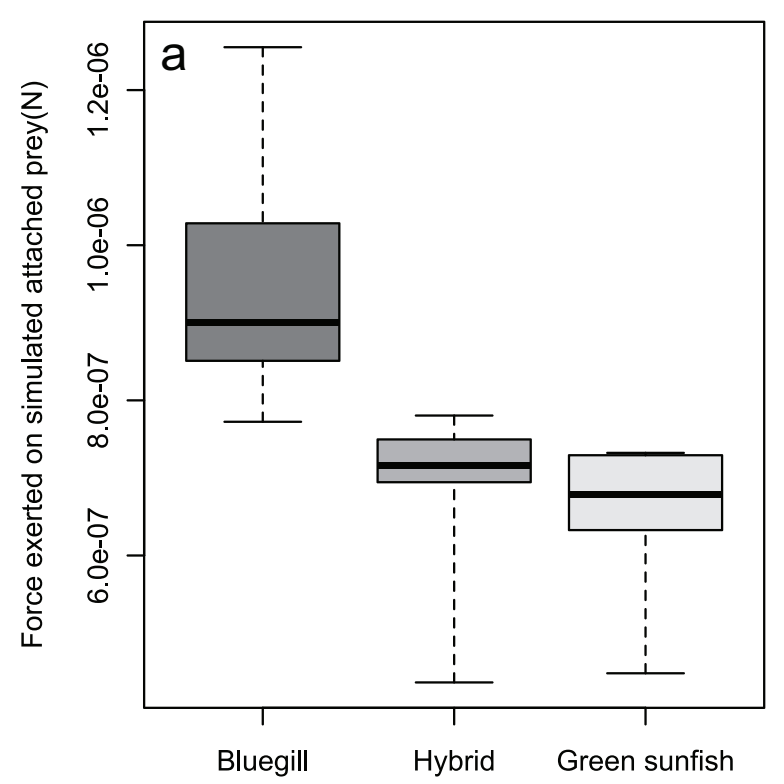

parisons). Bluegills and hybrids were not different from one another $(P=.34)$. We thus found that each parental species was predicted to have superior performance in capturing their preferred prey in their natural environment. The hybrids were not intermediate in their performance. Their performance on either prey was more similar to the parental species that did not specialize on that prey item, meaning that they were predicted to have low success rates in capturing either prey type. For both performance measures, hybrids were never statistically distinguishable from

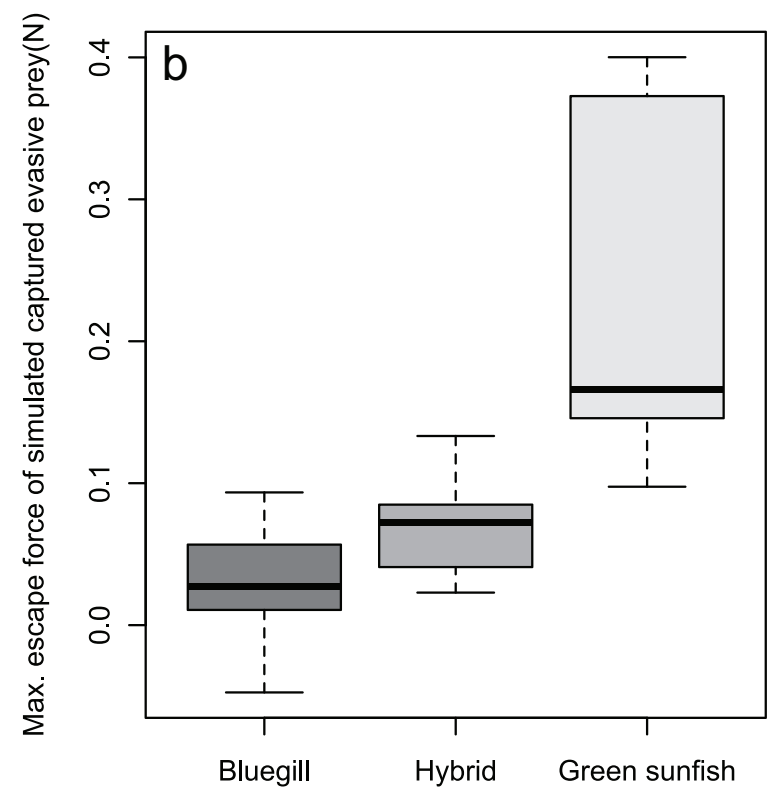

Figure 3: Comparison of SIFF (suction-induced force-field) performance values of simulated attached prey (a) and simulated evasive prey (b) performance for bluegill, hybrids, and green sunfish. Each box represents the difference between the $75 \%$ quartile and the $25 \%$ quartile; the bar represents the median, and the whiskers represent the extremes for each group. 
the worse-performing parental species. We also found that for attached prey, the hybrid species mean was farther from the species mean of bluegill than would be expected by chance $(P<.05)$. For evasive prey, the hybrid species mean was also farther from that for green sunfish than would be expected by chance $(P<.05)$. For both simulated prey types, hybrids were never farther from the worse-performing parental species than would be expected by chance $(P>.5)$.

\section{Discussion}

Our results give insights into the functional basis for reduced feeding performance in sunfish hybrids. We first explore kinematic and performance differences between the parental species, followed by hybrid performance, and then discuss the implications for future studies of natural hybridization.

Our kinematic results reveal a consistent pattern of divergence between the two parental species, bluegill and green sunfish. Our excursion PCA suggests that bluegill strike at close range, while green sunfish initiate strikes farther from the prey and close the distance more quickly. The excursion PCA also indicates that bluegill have less movement of the head and jaws during the strike than green sunfish, likely because the larger gape distance of the green sunfish involves more lower-jaw rotation and head elevation to reach full mouth opening. These differences match results from previous kinematic studies of the clade (Wainwright and Shaw 1999; Higham et al. 2006; Holzman et al. 2012).

Bluegill exhibited the highest performance on attached prey in SIFF simulations, likely because of their greater suction index, increasing the force exerted on prey. Green sunfish were able to capture substantially more evasive prey than bluegill in our SIFF simulations, in part because their larger gape projects their suction flow field farther forward and stalls prey acceleration. Hybrids exhibit kinematics intermediate to those of the two parental types, striking from an intermediate distance from the prey item with an intermediate-sized gape. However, in our SIFF performance simulations, the hybrids were always farther from the better-performing parental species than would be expected by chance.

Our results appear to reflect a nonlinear relationship between performance and morphology, with substantial implications for the study of hybrids in nature. Specifically, our performance data suggest a convex fitness set (Levins 1962), even though morphological traits suggest a linear relationship. This is not unexpected, as suction force itself does not have a linear relationship but decays exponentially from the mouth opening. A small increase or decrease in gape or a change in how prey is approached can have dramatic consequences for foraging success. These results are in line with previous work on complex relationships between form and function (Alfaro et al. 2005; Wainwright et al. 2005), suggesting that while morphology is often intimately linked to function, simple linear ecomorphological relationships may not be the rule.

This discrepancy between performance and morphology may have substantial implications for ecological speciation, particularly the common phenomenon of young species pairs in stickleback, whitefish, char, and centrarchids (Robinson and Wilson 1994). Typically, these species pairs involve trophic divergence between evasive limnetic prey and attached benthic prey (McGee et al. 2013), and the integrity of the species pair involves selection against hybrid individuals (Schluter 1995). The functional basis of trophic divergence is currently largely unknown in most postglacial systems, but in stickleback, the major loci separating benthics and limnetics are linked to trophic traits, including jaw protrusion and the size of epaxial musculature, and hybrids with intermediate values of these traits are selected against (Arnegard et al. 2014).

In our study, hybrids exhibited inferior performance on both parental resources relative to the appropriate parental specialist. It is also possible to imagine scenarios in which hybrid individuals have fitness equivalent to that of one or both parental species on parental resources. Such a hybrid would have all the benefits of one of its parental specialists while simultaneously enjoying moderate performance on the resources of the other potential specialist. If hybrid phenotypes are transgressive and reach outside the phenotype range of the parental types, hybrids may even exhibit higher performance than parental specialists or gain the ability to access novel resources. However, transgressive phenotypes have never been demonstrated in the Centrarchidae, even in intergeneric hybrids. Future work in other systems with more complex trophic traits may be necessary to demonstrate whether such relationships exist in nature and how they affect speciation processes (Selz et al. 2014).

In centrarchids, while hybrids do have impaired performance relative to parental types, other factors also prevent speciation. Hybrid sunfish are often sex biased, and male hybrids may exhibit impaired sperm motility in some hybrid populations (summarized in Bolnick and Near 2005 and Bolnick 2009). In addition, few data exist directly on high-level fitness in naturally produced hybrid sunfish, so the relative fitness effects of trophic morphology and reproductive characters are not known.

Natural sunfish hybrids were known to be morphologically intermediate, and our study of bluegill-green sunfish hybrids reveals that feeding kinematics largely track this pattern. However, performance phenotypes are more complex and do not always lead to intermediate function. This is likely to have important consequences both for ecolog- 
ical speciation and for other systems, such as some African cichlid radiations (Seehausen 2004), where hybridization itself may be driving increased rates of speciation and morphological evolution. A closer look into the functional consequences of hybridization in nature will be vital to understanding its contribution to biodiversity.

\section{Acknowledgments}

We thank C. L. Berg, J. S. Chow, M. Hymes, and M. Sperow for their assistance filming and digitizing sunfish and R. Kimsey for bringing these hybrids to our attention and providing background information and access to the habitat. We also thank D. N. Reznick and three anonymous reviewers for providing suggestions that improved the presentation of the study. This work was funded by National Science Foundation grant IOS-0924489.

\section{Literature Cited}

Agassiz, L. 1854. Notice of a collection of fishes from the southern bend of the Tennessee River, in the state of Alabama. American Journal of Science and Arts, series 2, 17:297-308, 353-365.

Alfaro, M. E., D. I. Bolnick, and P. C. Wainwright. 2005. Evolutionary consequences of many-to-one mapping of jaw morphology to mechanics in labrid fishes. American Naturalist 165:E140-E154.

Anderson, E., and G. L. Stebbins Jr. 1954. Hybridization as an evolutionary stimulus. Evolution 8:378-388.

Arnegard, M. E., M. D. McGee, B. Matthews, K. B. Marchinko, G. L. Conte, S. Kabir, N. Bedford, et al. 2014. Genetics of ecological divergence during speciation. Nature 511:307-311.

Bates, D., M. Maechler, B. Bolker, and S. Walker. 2014. lme4: linear mixed-effects models using "Eigen" and S4. R package version 1.1-5. https://cran.r-project.org/web/packages/lme4/index.html.

Bell, M. A., and M. P. Travis. 2005. Hybridization, transgressive segregation, genetic covariation, and adaptive radiation. Trends in Ecology and Evolution 20:358-361.

Bishop, K. L., P. C. Wainwright, and R. Holzman. 2008. Anterior-toposterior wave of buccal expansion in suction feeding fishes is critical for optimizing fluid flow velocity profile. Journal of the Royal Society Interface 5:1309-1316.

Bollman, C. H. 1891. A review of the Centrarchidae, or fresh-water sunfishes, of North America. Government Printing Office, Washington, DC.

Bolnick, D. I. 2009. Hybridization and speciation in centrarchids. Pages 39-69 in S. Cooke and D. P. Philipp, eds. Centrarchid fishes: diversity, biology and conservation. Wiley, Chichester.

Bolnick, D. I., and T. J. Near. 2005. Tempo of hybrid inviability in centrarchid fishes (Teleostei: Centrarchidae). Evolution 59:17541767.

Carroll, A. M., P. C. Wainwright, S. H. Huskey, D. C. Collar, and R. G. Turingan. 2004. Morphology predicts suction feeding performance in centrarchid fishes. Journal of Experimental Biology 207:3873-3881.

Cattani, M. V., and D. C. Presgraves. 2012. Incompatibility between $\mathrm{X}$ chromosome factor and pericentric heterochromatic region causes lethality in hybrids between Drosophila melanogaster and its sibling species. Genetics 191:549-559.

Cockayne, L., and H. H. Allan. 1926. The naming of wild hybrid swarms. Nature 118:623-624.

Collar, D. C., and P. C. Wainwright. 2006. Discordance between morphological and mechanical diversity in the feeding mechanism of centrarchid fishes. Evolution 60:2575-2584.

. 2009. Ecomorphology of centrarchid fishes. Pages 70-89 in S. Cooke and D. P. Philipp, eds. Centrarchid fishes: diversity, biology and conservation. Wiley, Chichester.

Cope, E. D. 1868. On the distribution of fresh-water fishes in the Allegheny region of southwestern Virginia. Journal of the Academy of Natural Sciences of Philadelphia, 2nd series, 6:207-247.

Coyne, J. A., and H. A. Orr. 1989. Patterns of speciation in Drosophila. Evolution 45:362-381.

- 2004. Speciation. Sinauer, Sunderland, MA.

Dixon, P. 2003. VEGAN, a package of R functions for community ecology. Journal of Vegetation Science 14:927-930.

Domenici, P., and R. Blake. 1997. The kinematics and performance of fish fast-start swimming. Journal of Experimental Biology 200: $1165-1178$.

Elliot, D. G. 1892. Hybridism, and a description of a hybrid between Anas boschas and Anas americana. Auk 9:160-166.

Ferry-Graham, L. A., P. C. Wainwright, and G. V. Lauder. 2003. Quantification of flow during suction feeding in bluegill sunfish. Zoology 106:159-168.

Girard, C. F. 1858. Notice upon new genera and new species of marine and fresh-water fishes from western North America. Proceedings of the Academy of Natural Sciences of Philadelphia 9: 200-202.

Grant, P. R., and Grant, B. R. 2014. Synergism of natural selection and introgression in the origin of a new species. American Naturalist 183:671-681.

Hedrick, T. L. 2008. Software techniques for two- and threedimensional kinematic measurements of biological and biomimetic systems. Bioinspiration and Biomimetics 3:034001. doi:10.1088/1748 $-3182 / 3 / 3 / 034001$.

Heliconius Genome Consortium. 2012. Butterfly genome reveals promiscuous exchange of mimicry adaptations among species. Nature 487:94-98.

Henshaw, H. W. 1885. Hybrid quail (Lophortyx gambeli $\times$ L. californicus). Auk 2:247-249.

Higham, T. E., S. W. Day, and P. C. Wainwright. 2006. Multidimensional analysis of suction feeding performance in fishes: fluid speed, acceleration, strike accuracy and the ingested volume of water. Journal of Experimental Biology 209:2713-2725.

Hollick, A. 1888. A recent discovery of hybrid oaks on Staten Island. Bulletin of the Torrey Botanical Club 15:303-309.

Holzman, R., D. C. Collar, R. S. Mehta, and P. C. Wainwright. 2012. An integrative modeling approach to elucidate suction-feeding performance. Journal of Experimental Biology 215:1-13.

Hubbs, C. L. 1955. Hybridization between fish species in nature. Systematic Zoology 4:1-20.

Hubbs, C. L., and L. C. Hubbs. 1932. Experimental verification of natural hybridization between distinct genera of sunfishes. Papers of the Michigan Academy of Science, Arts and Letters 15:427-437.

Jordan, D. S. 1877. Contributions to North American ichthyology based primarily on the collections of the United States National Museum. II. Bulletin of the National Museum, no. 10. Government Printing Office, Washington, DC. 
Kuznetsova, A., P. B. Brockhoff, and R. H. B. Christensen. 2013. lmerTest: tests for random and fixed effects for linear mixed effect models (lmer objects of lme4 package). $\mathrm{R}$ package version 2-0. https://cran.r-project.org/web/packages/lmerTest/index.html.

Langerhans, R. B. 2009. Morphology, performance, fitness: functional insight into a post-Pleistocene radiation of mosquitofish. Biology Letters 5:488-491.

Levins, R. 1962. Theory of fitness in a heterogeneous environment. I. The fitness set and adaptive function. American Naturalist 96 361-373.

Martin, N. H., and J. H. Willis. 2010. Geographical variation in postzygotic isolation and its genetic basis within and between two Mimulus species. Philosophical Transactions of the Royal Society B: Biological Sciences 365:2469-2478.

Martin, R. A., M. D. McGee, and R. B. Langerhans. 2015. Predicting ecological and phenotypic differentiation in the wild: a case of piscivorous fish in a fishless environment. Biological Journal of the Linnean Society 114:588-607.

McCormick, L. M. 1893. A hybrid tanager. Auk 10:302-303.

McGee, M. D., J. W. Reustle, C. E. Oufiero, and P. C. Wainwright. 2015. Data from: Intermediate kinematics produce inferior feeding performance in a classic case of natural hybridization. American Naturalist, Dryad Digital Repository, http://dx.doi.org/10.5061 /dryad.5g8c5.

McGee, M. D., D. Schluter, and P. C. Wainwright. 2013. Functional basis of ecological divergence in sympatric stickleback. BMC Evolutionary Biology 13:277. doi:10.1186/1471-2148-13-277.

McKay, C. L. 1881. A review of the genera and species of the family Centrarchidae, with a description of one new species. Proceedings of the United States National Museum 4:87-93.

Mill, P. J., and R. S. Pickard. 1975. Jet-propulsion in anisopteran dragonfly larvae. Journal of Comparative Physiology 97:329-338.

Müller, F. 1868. On Balanus armatus, and a hybrid between this species and Balanus improvisus, var. assimilis, Darw. Annals and Magazine of Natural History, 4th series, 1(6):393-412.

Near, T. J., D. I. Bolnick, and P. C. Wainwright. 2005. Fossil calibrations and molecular divergence time estimates in centrarchid fishes (Teleostei: Centrarchidae). Evolution 59:1768-1782.

Neff, N. A., and G. R. Smith. 1979. Multivariate analysis of hybrid fishes. Systematic Biology 28:176-196.

Orr, H. A., and M. Turelli. 2001. The evolution of postzygotic isolation: accumulating Dobzhansky-Muller incompatibilities. Evolution 55:1085-1094.

Oufiero, C. E., R. A. Holzman, F. A. Young, and P. C. Wainwright. 2012. New insights from serranid fishes on the role of trade-offs in suction-feeding diversification. Journal of Experimental Biology 215:3845-3855.

Robinson, B. W., and D. S. Wilson. 1994. Character release and displacement in fishes: a neglected literature. American Naturalist 144:596-627.

Sadzikowski, M. R., and D. C. Wallace. 1976. A comparison of the food habits of size classes of three sunfishes (Lepomis macrochirus Rafinesque, L. gibbosus (Linnaeus) and L. cyanellus Rafinesque). American Midland Naturalist 95:220-225.
Sankararaman, S., S. Mallick, M. Dannemann, K. Prüfer, J. Kelso, S. Pääbo, N. Patterson, and D. Reich. 2014. The genomic landscape of Neanderthal ancestry in present-day humans. Nature 507:354-357.

Schluter, D. 1995. Adaptive radiation in sticklebacks: trade-offs in feeding performance and growth. Ecology 76:82-90.

Seehausen, O. 2004. Hybridization and adaptive radiation. Trends in Ecology and Evolution 19:198-207.

Seehausen, O., G. Takimoto, D. Roy, and J. Jokela. 2008. Speciation reversal and biodiversity dynamics with hybridization in changing environments. Molecular Ecology 17:30-44.

Selz, O. M., K. Lucek, K. A. Young, and O. Seehausen. 2014. Relaxed trait covariance in interspecific cichlid hybrids predicts morphological diversity in adaptive radiations. Journal of Evolutionary Biology 27:11-24.

Taylor, E. B., J. W. Boughman, M. Groenenboom, M. Sniatynski, D. Schluter, and J. L. Gow. 2006. Speciation in reverse: morphological and genetic evidence of the collapse of a three-spined stickleback (Gasterosteus aculeatus) species pair. Molecular Ecology 15: 343-355.

Turelli, M., N. H. Barton, and J. A. Coyne. 2001. Theory and speciation. Trends in Ecology and Evolution 16:330-343.

Vonlanthen, P., D. Bittner, A. G. Hudson, K. A. Young, R. Müller, R. B. Lundsgaard-Hansen, D. Roy, S. Di Piazza, C. R. Largiader, and O. Seehausen. 2012. Eutrophication causes speciation reversal in whitefish adaptive radiations. Nature 482:357-362.

Wainwright, P. C. 1996. Ecological explanation through functional morphology: the feeding biology of sunfishes. Ecology 77:13361343.

Wainwright, P. C., M. E. Alfaro, D. I. Bolnick, and C. D. Hulsey. 2005. Many-to-one mapping of form to function: a general principle in organismal design? Integrative and Comparative Biology 45:256262.

Wainwright, P. C., A. M. Carroll, D. C. Collar, S. W. Day, T. E. Higham, and R. A. Holzman. 2007. Suction feeding mechanics, performance, and diversity in fishes. Integrative and Comparative Biology 47:96-106.

Wainwright, P. C., and S. W. Day. 2007. The forces exerted by aquatic suction feeders on their prey. Journal of the Royal Society Interface 4:553-560.

Wainwright, P. C., and B. A. Richard. 1995. Predicting patterns of prey use from morphology of fishes. Ecomorphology of Fishes 44: 97-113.

Wainwright, P. C., and S. S. Shaw. 1999. Morphological basis of kinematic diversity in feeding sunfishes. Journal of Experimental Biology 202:3101-3110.

Werner, E. E., and D. J. Hall. 1979. Foraging efficiency and habitat switching in competing sunfishes. Ecology 60:256-264.

West, J. L., and F. E. Hester. 1966. Intergeneric hybridization of centrarchids. Transactions of the American Fisheries Society 95:280288.

Associate Editor: David N. Reznick Editor: Troy Day 